\title{
PENILAIAN POSTUR OPERATOR DAN PERBAIKAN SISTEM KERJA DENGAN METODE RULA DAN REBA (STUDI KASUS)
}

\author{
Rizki Wahyuniardi ${ }^{*}$, Dhia Malika Reyhanandar \\ Program Studi Teknik Industri, Fakultas Teknik, Universitas Pasundan
}

(Received: April 24, 2017/ Accepted: February 1, 2018)

\begin{abstract}
Abstrak
Penelitian ini bertujuan untuk mendapatkan nilai postur pekerja dan memberikan rekomendasi perbaikan sistem kerja pemasangan Extrude IE yang dilakukan secara manual. Penelitian dilakukan melalui tahapan sebagai berikut : 1) Mendokumentasikan postur operator yang dilakukan saat berkerja; 2) Mengetahui skor, level resiko dan level tindakan dengan metode RULA; 3) Mengetahui skor, level resiko dan level tindakan dengan metode REBA 4) Memberikan solusi terhadap resiko ergonomi pada pekerja. Hasil perhitungan RULA dan REBA masing-masing bernilai 7 dan 9. Artinya sistem kerja perlu mendapatkan penyesuaian untuk perbaikan. Adapun penyesuaian yang dilakukan adalah dengan menyesuaikan meja kerja dengan menambahkan alas meja yang dapat berputar. Selain perbaikan meja kerja, posisi operator harus dalam keadaan duduk dalam proses perakitan. Hasil perhitungan RULA dan REBA setelah simulasi meja kerja dengan alas meja berputar adalah 3 dan 5. Hasil rekomendasi sitem tersebut dapat meminimalisir cidera otot pada operator.
\end{abstract}

Kata Kunci: Postur; RULA; REBA; Sistem Kerja

\begin{abstract}
This study aims to obtain the value of worker posture and provide recommendations for repair work system installation of Extrude IE done manually. The research is done through the following stages: 1) Document the posture of the operator performed while working; 2) Knowing the score, level of risk and level of action with RULA method; 3) Knowing the score, the level of risk and the level of action with the REBA method 4) Provide solutions to the risk of ergonomics to workers. The results of RULA and REBA calculations are worth 7 and 9 respectively. This means that the work system needs to get adjustments for improvement. The adjustment is done by adjusting the work table by adding a rotating table mat. In addition to the repair workbench, the position of the operator must be in a sitting state in the assembly process. The results of RULA and REBA calculations after the simulation of the workbench with the rotating pads are 3 and 5. The result of the recommendation of the system can minimize muscle injury to the operator.
\end{abstract}

Keywords: Posture; RULA; REBA; Work System

\section{PENDAHULUAN}

Aktivitas Manual Material Handling (MMH) yang tidak tepat dapat menimbulkan kerugian bahkan kecelakaan pada karyawan. Akibat yang ditimbulkan dari aktivitas MMH yang tidak benar salah satunya adalah keluhan muskuloskeletal. Keluhan muskoloskeletal adalah keluhan pada bagian-bagian otot skeletal yang dirasakan seseorang mulai dari keluhan yang sangat ringan sampai sangat sakit. Apabila otot menerima beban statis secara berulang dalam jangka waktu yang lama, akan menyebabkan keluhan berupa kerusakan pada sendi, ligamen dan tendon. (Kroemer and Grandjean, 1997 dalam

\footnotetext{
*) Penulis Korespondensi.

e-mail: dhia.malika@mail.unpas.ac.id
}

Nurliah, 2012).

Dari penelitian di Amerika Serikat diperoleh data bahwa pengusaha di industri swasta (yang merepresentasikan 75\% dari 135 juta pekerja) melaporkan sekitar 7 juta kasus cidera muskuloskeletal yang berhubungan dengan pekerjaan setiap tahun. Hal ini juga memperkirakan bahwa ada 5 sampai dengan 6 juta kasus pekerjaan sakit punggung yang berhubungan dengan setiap tahun di seluruh penduduk AS bekerja, yang menyebabkan hilangnya 100 juta hari kerja. Gangguan muskuloskeletal ini juga menelan biaya yang besar, yang jika digabungkan dengan biaya tidak langsung kepada pengusaha (hilang produktivitas) dan individu yang terkena, mencapai $1 / 3$ biaya kompensasi pekerja di AS (Delleman et. al., 2004 dalam Nurliah, 2012). 
Masalah ergonomi akan lebih banyak terjadi pada kondisi pekerjaan-pekerjaan yang sering mengangkat, membawa, menarik dengan cara manual, mengulangi gerakan yang sama di seluruh hari kerja, bekerja di posisi janggal atau statis, mengangkat barang berat atau canggung, menggunakan kekuatan berlebihan untuk melakukan tugas, terkena getaran yang berlebihan atau bekerja pada suhu ekstrim, dan perkerjaan merakit dengan kecepatan merakit yang tinggi (Aah Nurliah, 2012).

P.T. "A" merupakan perusahaan swasta di bidang industri manufaktur yang merakit produk penerangan jalan umum (PJU). Produk yang dibuat yaitu lampu jalan, lampu tenaga solar (surya), lampu taman dan LED Luminer. Dalam pembuatan produk lampu jalan yang relatif kontinyu, terdapat perakitan manual untuk merakit bagian Extrude IE lampu PJU. Dari pengamatan awal, posisi kerja operator untuk proses ini memiliki resiko pegal dan kelelahan.

Dalam ergonomi, dikenal pendekatan RULA (Rapid Upper Limb Assessment) (Lynn, 1994) dan REBA (Rapid Entire Body Assessment) (Hignett, 2000). RULA menilai postur, gaya, dan gerakan suatu aktivitas kerja yang berkaitan dengan penggunaan anggota tubuh bagian atas, sedangkan REBA digunakan untuk menilai postur leher, punggung, lengan, pergelangan tangan dan kaki (Singh, 2014; Tobing, 2016). Dengan pendekatan ini diharapkan resiko cedera dari pekerja dapat ditekan, biaya kesehatan akibat postur yang salah dapat dikurangi, kenyamanan pekerja dapat ditingkatkan dan meningkatkan produktivitas dan kinerja pekerja.

Rumusan masalah dari penelitian ini adalah bagaimana penilaian postur operator dengan menggunakan metode RULA dan REBA dan rekomendasi yang dapat diberikan untuk perbaikan sistem untuk operator pemasangan Extrude IE PJU. Tujuan penelitian ini adalah mengetahui nilai postur pekerja menggunakan metode RULA dan REBA serta rekomendasi perbaikan untuk postur kerja operator pemasangan Extrude IE PJU.

\section{KERANGKA PEMECAHAN MASALAH}

Alur pemecahan masalah penelitian dapat dijelaskan sebagai berikut:

1. Mengamati pekerjaan yang dianalisis dengan mengambil gambar operator dalam posisi kerjanya

2. Menghitung sudut antara posisi kerja dan postur normal

3. Mengisi scoring untuk setiap posisi kerja pada lembar penilaian RULA

4. Menghitung skor RULA

5. Kembali ke urutan ke 2

6. Mengisi scoring untuk setiap posisi kerja pada lembar penilaian REBA

7. Menghitung skor REBA

8. Menganalisis

9. Membuat kesimpulan dan saran

\section{HASIL DAN PEMBAHASAN}

\section{Pengumpulan Data}

Data yang dikumpulkan di P.T. "A" adalah postur tubuh operator dalam melakukan pekerjaan pemasangan Extrude IE PJU sebanyak 220 unit/ bulan atau 8 unit/ hari. Dokumentasi diambil adalah foto postur operator yang dianalisis dan dapat dilihat pada Gambar 1.

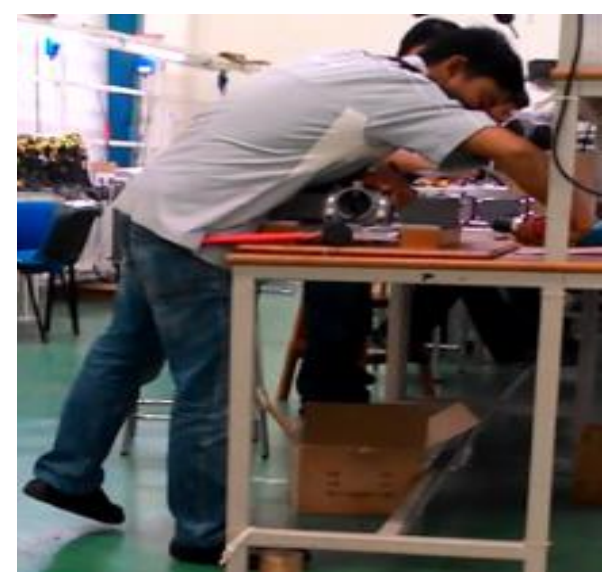

Gambar 1. Postur Operator yang Dianalisis Sumber : Peneliti, 2017

\section{Pengolahan Data: RULA}

Untuk memperoleh nilai postur operator berdasarkan RULA, dibutuhkan pengisian Tabel A, B dan $\mathrm{C}$ yang diterangkan dalam 15 langkah. Tabel $\mathrm{A}$ berisi penilaian mengenai lengan dan pergelangan tangan, tabel B untuk leher, punggung dan kaki serta tabel $\mathrm{C}$ yang merupakan rekapitulasi nilai akhir di tabel A dan tabel B.

Untuk menjelaskan, diberikan contoh lengkap penilaian untuk 1 (satu) postur saja, yaitu langkah ke1. Sedangkan untuk lengkapnya akan disampaikan dalam Tabel 1.

\section{Langkah 1 RULA: Menilai Posisi Lengan Atas}

Dari Gambar 1., potongan gambar untuk dapat mengukur sudut yang terjadi pada posisi lengan atas diperlihatkan pada Gambar 2. Terlihat bahwa sudut yang terjadi adalah $89,06^{\circ}$.

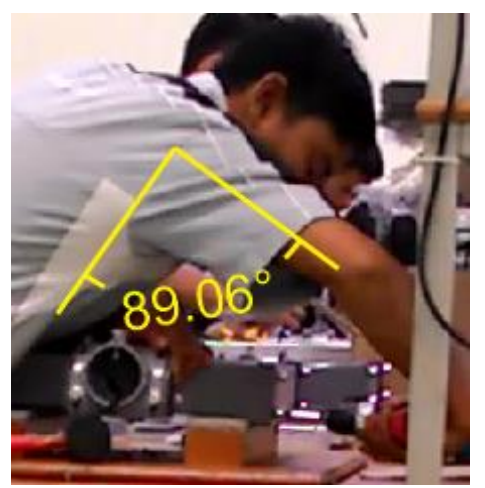

Gambar 2. Postur dan Sudut Posisi Lengan Atas yang Dibentuk oleh Operator yang Dianalisis Sumber : Peneliti, 2017 
Dari Gambar 2., sesuai dengan pendekatan RULA, maka nilai postur lengan atas yang dibentuk oleh operator sebesar $45^{\circ}-90^{\circ}$ adalah 3. Selanjutnya untuk Langkah 2 hingga 16, diringkas dalam Tabel 1.

Tabel 1. Ringkasan Langkah 1 Hingga 16 RULA

\begin{tabular}{|c|c|c|}
\hline Langkah & Sudut $\left({ }^{\circ}\right)$ / Keterangan & Nilai \\
\hline 1 & $89,06^{\circ}$ & +3 \\
\hline 2 & $153,56^{\circ}$ & +2 \\
\hline 3 & $80,47^{\circ}$ & +3 \\
\hline 4 & Terpelintir & +1 \\
\hline 5 & $\begin{array}{l}\text { Nilai pada baris } 3 \text { dan } 2 \\
\text { Nilai pada kolom } 3 \text { dan } 1\end{array}$ & +4 \\
\hline 6 & Postur sebagian statis & +1 \\
\hline 7 & Beban $<2 \mathrm{~kg}$ & 0 \\
\hline 8 & $\begin{array}{c}\text { Jumlah nilai dari } \\
\text { langkah }(5+6+7)\end{array}$ & 5 \\
\hline 9 & $66,23^{\circ}$ & +3 \\
\hline $10+10 a$ & \multirow{2}{*}{$\begin{array}{l}46,01^{\circ}+\text { Punggung } \\
\text { menghadap kanan }\end{array}$} & $\begin{array}{l}+3 \\
+1 \\
\end{array}$ \\
\hline 10 & & +4 \\
\hline 11 & $\begin{array}{c}\text { Tidak tersangga dengan } \\
\text { baik }\end{array}$ & +2 \\
\hline 12 & $\begin{array}{c}\text { Nilai pada baris } 3 \\
\text { Nilai pada kolom } 4 \text { dan } 2\end{array}$ & +6 \\
\hline 13 & Postur sebagian statis & +1 \\
\hline 14 & Beban $<2 \mathrm{~kg}$ & 0 \\
\hline 15 & $\begin{array}{c}\text { Jumlah nilai dari } \\
\text { langkah }(12+13+14)\end{array}$ & +7 \\
\hline 16 & $\begin{array}{l}\text { Jumlah nilai dari } \\
\text { langkah }(8+15)\end{array}$ & +7 \\
\hline
\end{tabular}

Dari nilai di langkah 16 ini maka diketahui bahwa nilai kondisi aktual adalah 7 yang berarti investigasi dan perubahan dari kondisi sistem kerja perlu segera dilakukan.

\section{Pengolahan Data: REBA}

Serupa dengan pengolahan RULA, REBA membutuhkan pengisian tabel $\mathrm{A}, \mathrm{B}$ dan $\mathrm{C}$ yang diterangkan dalam 15 langkah. Tabel A berisi penilaian mengenai lengan dan pergelangan tangan, tabel B untuk leher, punggung dan kaki serta tabel C yang merupakan rekapitulasi nilai akhir di tabel A dan tabel B.

Untuk menjelaskan, diberikan contoh lengkap penilaian untuk 1 (satu) postur saja, yaitu langkah ke1. Sedangkan untuk lengkapnya akan disampaikan dalam Tabel 2.

\section{Langkah 1 REBA: Menilai Posisi Leher}

Dari Gambar 1., potongan gambar untuk dapat mengukur sudut yang terjadi pada posisi leher atas diperlihatkan pada Gambar 3. Terlihat bahwa sudut yang terjadi adalah $66,23^{\circ}$.

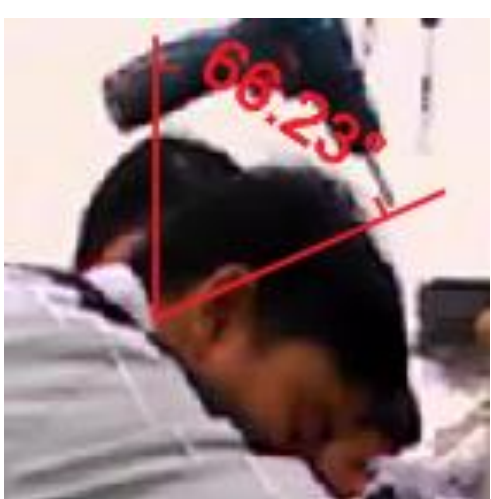

Gambar 3. Postur dan Sudut Posisi Leher yang Dibentuk oleh Operator yang Dianalisis Sumber : Peneliti, 2017

Dari Gambar 3., sesuai dengan pendekatan REBA, maka nilai postur leher yang dibentuk oleh operator sebesar $66,23^{\circ}$ yang artinya lebih besar dari $20^{\circ}$ sehingga dinilai +2 . Dapat dilihat pula jika posisi leher menekuk ke arah kanan, maka nilai ditambah +1. Selanjutnya untuk Langkah 2 hingga 15 , diperlihatkan pada Tabel 2.

Tabel 2. Ringkasan Langkah 1 Hingga 15 REBA

\begin{tabular}{|c|c|c|}
\hline Langkah & Sudut $\left({ }^{\circ}\right)$ / Keterangan & Nilai \\
\hline $1+1 \mathrm{a}$ & \multirow{2}{*}{$\begin{array}{c}66,23^{\circ}+\text { Tertekuk ke } \\
\text { kanan }\end{array}$} & $\begin{array}{l}+2 \\
+1\end{array}$ \\
\hline 1 & & +3 \\
\hline $2+2 a$ & \multirow{2}{*}{$\begin{array}{c}46,01^{\circ}+\text { Tertekuk ke } \\
\text { kanan }\end{array}$} & $\begin{array}{l}+2 \\
+1\end{array}$ \\
\hline 2 & & +3 \\
\hline $3+3 a$ & \multirow{2}{*}{$\begin{array}{l}\text { Salah satu kaki terangkat } \\
\quad+\text { Menekuk } 10,05^{\circ}\end{array}$} & $\begin{array}{l}+2 \\
+1\end{array}$ \\
\hline 3 & & +3 \\
\hline 4 & $\begin{array}{c}\text { Nilai pada baris } 3 \\
\text { Nilai pada kolom } 3 \text { dan } 3\end{array}$ & 6 \\
\hline 5 & Beban $<4 \mathrm{~kg}$ & +0 \\
\hline 6 & $\begin{array}{l}\text { Jumlah nilai dari } \\
\text { langkah }(4+5)\end{array}$ & 6 \\
\hline 7 & $89,06^{\circ}$ & +3 \\
\hline 8 & $153,56^{\circ}$ & +2 \\
\hline $9+9 a$ & \multirow{2}{*}{$80,47^{\circ}+$ Dibelokkan } & $\begin{array}{l}+2 \\
+1\end{array}$ \\
\hline 9 & & +3 \\
\hline 10 & $\begin{array}{c}\text { Nilai pada baris } 3 \\
\text { Nilai pada kolom } 2 \text { dan } 3\end{array}$ & 5 \\
\hline 11 & $\begin{array}{c}\text { Skor pegangan dan grip } \\
\text { baik }\end{array}$ & +0 \\
\hline 12 & $\begin{array}{c}\text { Jumlah nilai dari } \\
\text { langkah }(10+11)\end{array}$ & 5 \\
\hline 13 & Skor aktivitas & +1 \\
\hline 14 & $\begin{array}{l}\text { Nilai pada baris } 6 \\
\text { Nilai pada kolom } 5\end{array}$ & 8 \\
\hline 15 & $\begin{array}{c}\text { Jumlah nilai dari } \\
\text { langkah }(13+14)\end{array}$ & 9 \\
\hline
\end{tabular}


Dari nilai di langkah 15 ini maka diketahui bahwa nilai kondisi aktual adalah 9 yang berarti kondisi saat ini sangat beresiko tinggi (terhadap cedera) dan perlu menerapkan perubahan terhadap sistem kerja.

\section{Analisis Perbaikan Sistem Kerja}

Merujuk kepada hasil pengolahan postur kerja menggunakan RULA dan REBA yang berturut-turut menghasilkan nilai 7 dan 9, maka dapat diketahui bahwa postur kerja saat ini memerlukan perubahan segera. Dari kondisi saat ini, penyesuaian dilakukan terhadap meja kerja operator.

Meja kerja merupakan alat bantu utama yang dipergunakan oleh operator. Kondisi meja kerja yang ada saat ini menjadi faktor utama yang menyebabkan postur operator. Dari hasil perhitungan RULA dan REBA, tercatat beberapa postur operator memberikan nilai yang kurang baik. Salah satunya adalah postur pergelangan tangan yang membentuk sudut $80,47^{\circ}$. Oleh karenanya perlu dilakukan penyesuaian kondisi meja kerja dengan merubah alas meja kerja statis menjadi dinamis.

Berikut ini adalah rancangan meja kerja yang dibuat untuk dapat memperbaiki postur operator. Penyesuaian meja kerja dapat dilihat pada Gambar 4 hingga Gambar 7.

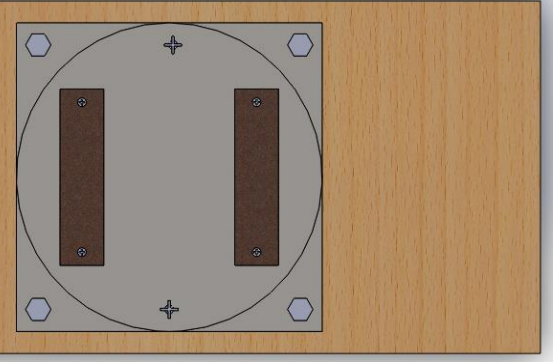

Gambar 4. Rancangan Meja Kerja (Tampak Atas) Sumber: Pengolahan data, 2017

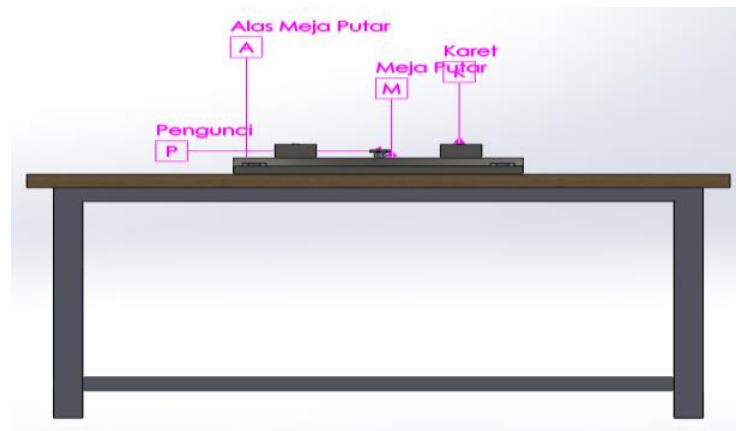

Gambar 5. Rancangan Meja Kerja (Tampak Depan) Sumber: Pengolahan data, 2017

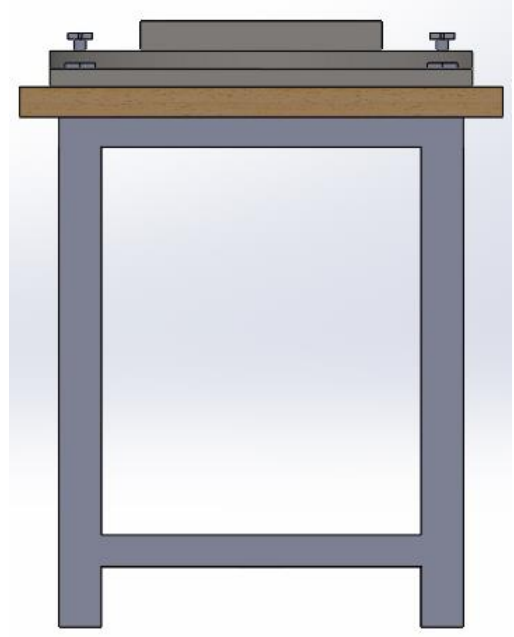

Gambar 6. Rancangan Meja Kerja (Tampak Samping) Sumber: Pengolahan data, 2017 


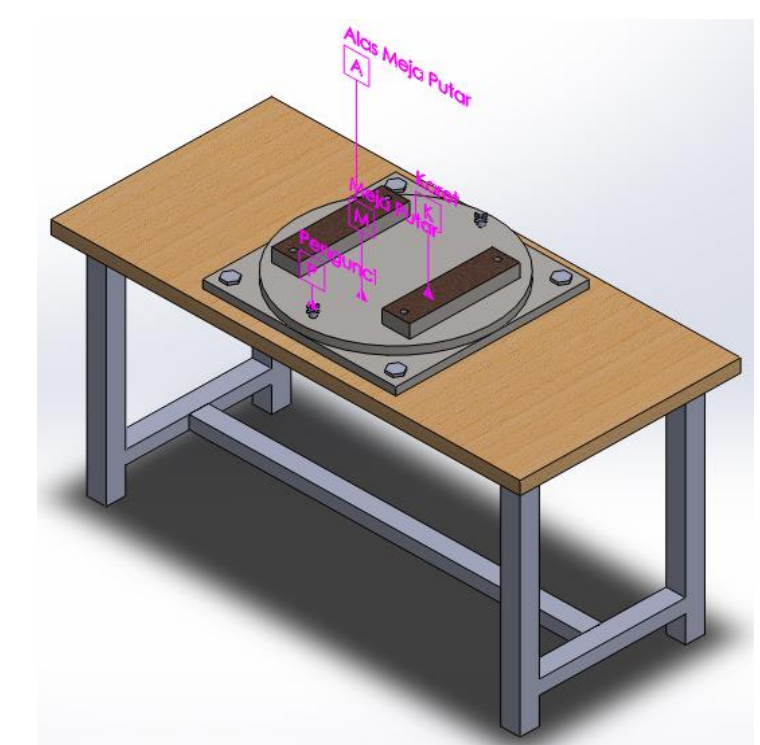

Gambar 7. Rancangan Meja Kerja (Tampak Isometri) Sumber: Pengolahan data, 2017

Dari penyesuaian meja kerja, dilakukan simulasi penyesuaian postur kerja operator. Simulasi dilakukan secara manual dengan mempertimbangkan operator pada posisi duduk, mempergunakan RULA dan REBA. Hasil yang diperoleh dapat dilihat pada Tabel 3.

Tabel 3. Ringkasan Nilai RULA dan REBA

(Awal dan Simulasi)

\begin{tabular}{|c|c|c|c|c|c|}
\hline \multirow{2}{*}{ Langkah } & \multicolumn{2}{|c|}{ Nilai RULA } & \multirow{2}{*}{ Langkah } & \multicolumn{2}{|c|}{ Nilai REBA } \\
\hline & Lama & Simulasi & & Lama & Simulasi \\
\hline \multirow{3}{*}{1} & \multirow{3}{*}{+3} & \multirow{3}{*}{+3} & $1+$ & +2 & +1 \\
\hline & & & $1 \mathbf{a}$ & +1 & +0 \\
\hline & & & 1 & +3 & +1 \\
\hline \multirow{3}{*}{2} & \multirow{3}{*}{+2} & \multirow{3}{*}{+2} & $2+$ & +2 & +2 \\
\hline & & & $2 \mathbf{a}$ & +1 & +0 \\
\hline & & & 2 & +3 & +2 \\
\hline \multirow{3}{*}{3} & \multirow{3}{*}{+3} & \multirow{3}{*}{+1} & $3+$ & +2 & +1 \\
\hline & & & $\mathbf{3 a}$ & +2 & +2 \\
\hline & & & 3 & +4 & +3 \\
\hline 4 & +1 & +1 & 4 & +6 & +4 \\
\hline 5 & +4 & +3 & 5 & +0 & +0 \\
\hline 6 & +1 & +1 & 6 & 6 & 4 \\
\hline 7 & +0 & +0 & 7 & +3 & +3 \\
\hline 8 & 5 & 4 & 8 & +2 & +2 \\
\hline \multirow{3}{*}{9} & \multirow{3}{*}{+3} & \multirow{3}{*}{+2} & $9+$ & +2 & +1 \\
\hline & & & $9 \mathbf{a}$ & +1 & +0 \\
\hline & & & 9 & +3 & +1 \\
\hline $10+$ & +2 & +2 & \multirow{3}{*}{10} & \multirow{3}{*}{5} & \multirow{3}{*}{4} \\
\hline $10 \mathbf{a}$ & +1 & +0 & & & \\
\hline 10 & +1 & +2 & & & \\
\hline 11 & +4 & +1 & 11 & +0 & +0 \\
\hline 12 & 2 & 2 & 12 & 5 & 4 \\
\hline 13 & +6 & +1 & 13 & +1 & +1 \\
\hline 14 & +1 & +0 & 14 & 8 & 4 \\
\hline 15 & 0 & 3 & 15 & 9 & 5 \\
\hline 16 & 7 & 3 & & & \\
\hline
\end{tabular}

Sumber : Pengolahan data, 2017 
Dari Tabel 3, dapat dilihat bahwa penyesuian meja kerja dengan menambah alas meja berputar dan posisi operator duduk secara simulasi dapat memperbaiki nilai postur kerja menurut pendekatan RULA dan REBA.

\section{KESIMPULAN}

Berdasarkan hasil pengolahan data dan analisa yang telah dibuat maka dapat ditarik kesimpulan sebagai berikut :

1. Hasil akhir nilai postur operator pada perakitan lampu PJU di bagian perakitan Extrude IE di P.T. "A" dengan metode RULA adalah 7 yang berarti postur tubuh harus diinvestigasi lebih lanjut dan perubahan postur dilakukan dengan segera. Sedangkan hasil akhir nilai metode REBA adalah 10, yang berarti postur tubuh berisiko tinggi mendapatkan cedera, harus dilakukan penyelidikan dan menerapkan perubahan.

Hasil akhir postur operator yang telah berubah menggunakan meja alas putar pada perakitan lampu PJU di bagian perakitan Extrude IE di P.T. "A" dengan metode RULA adalah 3 yang berarti bahwa postur tubuh harus diinvestigasi lebih lanjut dan perubahan postur dilakukan dengan segera. Nilai akhir postur operator pada perakitan lampu PJU di bagian perakitan Extrude IE di P.T. "A" dengan metode REBA adalah 5 yang menyatakan bahwa postur tubuh yang dilakukan berisiko menengah mendapatkan cedera, harus dilakukan penyelidikan dan segera menerapkan perubahan.

Dapat dilihat skor akhir RULA dan REBA sebelum dan sesudah perubahan postur ketika ada alat atau meja kerja yang dapat membantu perubahan postur kerja dan mengurangi risiko cedera yang didapatkan oleh operator.

2. Rekomendasi sistem untuk operator perakitan atau pemasangan Extrude IE lampu di P.T. "A" yaitu:

a. Menggunakan meja dengan alas yang dapat berputar memudahkan operator dalam merakit Extrude IE dan mengurangi risiko cedera.

b. Mewajibkan seluruh operator bekerja dalam keadaan duduk pada saat melakukan proses perakitan lampu PJU.

c. Operator melakukan istirahat ketika sudah terasa pegal dan melakukan peregangan.

\section{DAFTAR PUSTAKA}

Nurliah, Aah, 2012, Analisis Resiko Musculoskeletal Disorders (MSDs) pada Operator Forklift di PT LLI Tahun 2012, Tesis, Universitas Indonesia

Singh, Tarwinder, Jaswindwer Singh, 2014, Ergonomi Evaluation of Industrial Tasks In Indian Electronics Industries, International Journal of Science and Research (IJSR), Vol. 3, Issue 6, pp. 295-300

Hignett, Sue and Lynn McAtamney, 2000, Rapid Entire Body Assessment (REBA), Applied Ergonomics, Vol. 31, pp. 201-205

Lynn, McAtamney and E. Nigel Corlett, 1994, RULA: a survey method for the investigation of world-related upper limb disorders, Applied Ergonomics, Vol. 24, No. 2, pp. 91-99.

Corlett, E. Nigel, 1976, A technique of assessing postural discomfort, Ergonomic, Vol. 19, No. 2, pp. 175-182.

Tobing, dkk, 2016, Perancangan Alat Bantu Perakitan Helm Untuk Menurunkan Risiko Kerja Operator, J. Ergonomi dan K3, Vol. 1, No. 1, hal. $14-24$ 